\title{
O desencanto histórico e religioso no romance As naus, de Antonio Lobo Antunes
}

\author{
Enéias Farias Tavares*
}

\begin{abstract}
Resumo: No romance As naus (1988), António Lobo Antunes reescreve a história de um grupo de homens que saíram de sua terra como conquistadores e catequizadores e que, no seu retorno, observaram uma nação que desconhecem. Nesse artigo, trabalharemos inicialmente a releitura histórica que Lobo Antunes fez de algumas personalidades da história e da cultura portuguesa. Posteriormente, planejamos centrar nossa análise no nono capítulo do romance, no qual a relação entre Francisco Xavier e Fernão Mendes Pino é ilustrativa ao demonstrar o falso discurso catequizador dos navegadores portugueses. Essa análise visa uma leitura crítica de As naus, tentando ver no romance uma nova construção imaginária do discurso histórico sobre as conquistas portuguesas do século XV e XVI.
\end{abstract}

Palavras-Chave: discurso histórico; releitura contemporânea, António Lobo Antunes; As naus

\begin{abstract}
In the novel As Naus (1988), António Lobo Antunes rewrites the story of a group of men who left their land as conquerors and catechists and in their return found a nation that they didn't know. In this paper, we will work initially with the historical rereading that Lobo Antunes made of some personalities of the Portuguese history and culture. Later, we will focus our analysis on the ninth chapter of the novel, in which the relationship between Francis Xavier and Fernão Mendes Pino is illustrative, showing the fake evangelistic speech of the Portuguese navigators. This analysis aims at presenting a critical reading of As naus, trying to observe in the novel a new imaginary construction of the historical discourse about the Portuguese conquests of the fifteenth and sixteenth centuries.
\end{abstract}

Keywords: historical discourse; contemporary rereading; António Lobo Antunes; As naus

Descobri o que os escritores sempre souberam, (e nos disseram muitas e muitas vezes): os livros sempre falam sobre outros livros, e toda história conta uma história que já foi contada.

Umberto Eco, O Nome da Rosa

Como nunca logrou reconstituir a sua numerosa colecção de conchas de rio onde as sereias cantavam baixinho saudades indistintas, substituiu-as por fotografias de cavalheiros de patilhas e de damas de sobrolhos terríveis, compradas em feiras de província no desejo de inventar para si mesmo o passado que perdera.

António Lobo Antunes, As naus

Em 1572, o português Luís de Camões terminou a escrita do épico Os Lusíadas, pelo qual recebeu uma pensão de quinze mil reis anuais do rei Dom Sebastião. Essa bonificação foi prova de que a obra, dedicada ao próprio rei, foi reconhecida em seu momento de criação por ilustrar um período de Portugal cujas glórias, conquistas e vitórias ficariam, por meio do discurso épico, gravadas no imaginário de toda nação. Ironicamente, o poeta morreu em

\footnotetext{
* Formado em Letras e Mestre em Estudos Literários pela Universidade Federal de Santa Maria. Atualmente, doutorando pela mesma instituição e bolsista Capes.
} 
desgraça, sendo enrolado num lençol e sepultado em terreno não consagrado, sem os serviços fúnebres católicos vigentes. A morte de Camões, fim pouco diferente de muitos de seus contemporâneos, nobres ou não, ilustra que as glórias portuguesas cantadas nos Lusíadas eram ilusórias, sobretudo para o poeta que as cantou.

Quatro séculos depois, outro português publica um romance que reinterpreta a memória dos grandes portugueses do passado, fazendo ficcionalmente retornar à pátria nos dias atuais. Falamos de As naus, de António Lobo Antunes. Nele, o narrador reconta a história de um grupo de homens que saíram de sua terra como viajantes que objetivaram conquistas e glórias para o povo português. Aventura e intento narrado no poema de Camões. Nesse retorno hipotético, o narrador de Lobo Antunes apresenta um grupo de homens que fracassaram em seu anterior objetivo e que, doentes, esgotados e mentalmente confusos, voltam para uma pátria que desconhecem, uma nação que não mais se recorda deles enquanto pretensos heróis e conquistadores.

Nesse artigo, trabalharemos inicialmente com a nova caracterização ficcional e histórica que Lobo Antunes faz de algumas personalidades da história e da cultura portuguesa. Posteriormente, centraremos nossa análise no nono capítulo do romance, no qual a relação entre Francisco Xavier e Fernão Mendes Pino é ilustrativa ao demonstrar na contemporaneidade das personagens o falso discurso catequizador dos navegadores portugueses dos séculos dezesseis e dezessete. Essa análise visa uma leitura crítica de As naus, tentando ver no romance uma nova construção imaginária do discurso histórico sobre as conquistas portuguesas do século XV e XVI.

Em 25 de Abril de 1974, Portugal se liberta da ditadura do Estado Novo, que tinha na figura de Antônio Oliveira Salazar seu principal líder. No poder, Salazar fez uso do poema de Camões, Os Lusíadas, como suporte ideológico e demagógico com o objetivo de elevar o sentimento de superioridade do povo português. Além disso, Salazar lia o poema como uma comprovação de que pertencia ao homem português conquistar, dominar e explorar, como fez a nação portuguesa nos séculos catorze e quinze. Adma Fadul Muhana, professora de literatura portuguesa da USP, comentando a reviravolta que essa revolução causou, afirma:

Depois da Revolução dos Cravos, evidentemente, aboliu-se o conceito de raça como hipérbole para o 'ilustre peito lusitano'. À imagem do português colonizador sucedeu-se aquela do português emigrante, espalhado pelas diversas comunidades no mundo, muito por conta do fracasso das políticas sociais do Estado Novo. (...) O poeta Camões, de nauta e soldado na Índia, conquistador a serviço da pátria, converte-se, então, em símbolo do português desterrado, expatriado, emigrado, em suma. (2006, p. 73) 
É exatamente nessa releitura da obra do poeta português, como também de todos os ideais sociais e políticos lusitanos, que se encontra a obra de António Lobo Antunes. Pertencente a uma geração de romancistas pós Revolução dos Cravos, Antunes marca suas narrativas com uma temática desmistificadora que relê o passado de forma irônica. No caso de As naus, o fio condutor do romance é o retorno dos grandes navegadores, cronistas e catequizadores do passado. Vindos da antiga colônia em África, especialmente de uma Angola agora independente, as personagens do romance reentram no mundo moderno e num estranho território português com estranheza similar ao que encontraram ao adentrar terras desconhecidas. Fazendo menção aos conflitos libertadores coloniais e à crise durante a revolução que pôs fim ao período ditatorial português, Antunes aborda o re-patriamento da sua terra por parte daqueles que um dia a deixaram para conquistar terras longínquas.

Tal visão, longe de ser uniforme, como no discurso épico camoniano, por exemplo, apresenta grande número de experimentação narrativa e temporal. No caso dessa última, experimentação totalmente anacrônica, pelo modo como o narrador e Lobo Antunes apresenta uma completa fusão entre o tempo presente de sua narrativa e o passado histórico de suas personagens. Nesse sentido, se Lobo Antunes constrói em seu romance múltiplos discursos criados a partir de múltiplos pontos de vista, vejamos como as idéias de Gérard Genette, em Discurso da Narrativa, pode ajudar a estudá-los.

Primeiramente, Genette define por anacronia, dentro do discurso literário, as "diferentes formas de discordância entre a ordem da história e a da narrativa" (1995, p. 35). Embora as reflexões de Genette estejam centrados na forma literária de Marcel Proust, usando o termo história como sinônimo de trama ou fábula, identificamos em seu conceito o desregramento entre o tempo da enunciação e o tempo ao qual se faz referência. Genette exemplifica isso mencionando que Proust levou mais de dez anos para escrever seu livro enquanto que boa parte da trama se passa em poucos dias. Nesse sentido, essa anacronia romanesca diz respeito a um tempo organizado, não do ponto de vista histórico temporal do autor, e sim do ponto de vista ficcional do narrador. No caso de Antunes, todos os seus narradores são senhores de seus respectivos tempos de enunciação e de referenciação. Meses, anos, décadas - séculos do ponto de vista do discurso histórico - são rapidamente perpassados pelos relatos das vivências e impressões das personagens. Para o autor, em sua noção de anacronia textual, que pode ser associada à técnica narrativa escolhida por Lobo Antunes, 
Tudo se passa, com efeito, como se a narrativa, apanhada entre aquilo que conta (a história) e o que a conta (a narração, guiada aqui pela memória), não tivesse escolha senão entre a dominação da primeira (é a narrativa clássica) e a segunda (é a narrativa moderna, que com Proust se inaugura). (1995, p. 154)

A preocupação de Genette em diferenciar narrativa clássica e moderna diz respeito à diferença entre o aspecto temporal nos épicos homéricos e no discurso proustiano. No primeiro teríamos marcações temporais bem definidas. Sabe-se que a guerra de Tróia dura dez anos e que dez anos é o tempo que Ulisses leva para retornar à Ítaca. Não que não se possa ter essa mesma medida no romance de Proust, mas nele o narrador é guiado pela subjetividade memorial que foge da exatidão temporal exatamente por narrar as intermináveis variações existenciais do personagem. É um tempo mais psicológico do que cronológico, como se compreende a noção de tempo no épico de Homérico.

Em As naus, tais impressões existenciais são de ordem mnemônica. Evidência disso é que nenhuma das personagens define objetivamente a passagem do tempo. $O$ discurso histórico - pertencente tanto ao período de expansão português do século XVI quanto aos acontecimentos políticos do século XX, como a Revolta dos Cravos - se mescla ao discurso subjetivo dos personagens. Estes, ao ignorarem quatro séculos de transformações sociais e políticas, reforçam unicamente suas impressões memorialistas sobre o deixar a pátria e o voltar a ela. Séculos viram anos na narrativa múltipla do narrador múltiplo e temporalmente cambiante de Antunes.

Tendo em vista essa variação de vozes narrativas presentes no romance, o que se nota é uma dificuldade em se conceituar ou definir um determinado tipo de narrador. Genette continua problematizando o estudo da narrativa literária ao comentar o papel do próprio narrador, no quinto capítulo de Discurso da Narrativa. Genette menciona que o papel do narrador pode ser apreendido por se estudar a relação desse narrador com a diegese - conjunto de ações que organizam e constituem uma narrativa do ponto de vista cronológico.

A partir dessa relação, Genette formula a possibilidade de encontrarmos três diferentes narradores: o narrador autodiegético, que corresponderia à ideia que temos de narrador personagem protagonista, escrito em primeira pessoa; o do narrador homodiegético, sendo o que narra o que testemunhou, não protagonizando as principais ações do romance; e o narrador heterodiegético, que corresponderia a um narrador onisciente que narra de fora da história (1995, p. 245-249). Qual deles é usado por Lobo Antunes em As naus? Num romance tradicional, esperar-se-ia que o autor escolhe-se um deles para construir sua narrativa. Em Antunes, o autor, ao construir seu narrador romanesco, faz uso de todos eles. 
O autor de As naus apresenta seus narradores como um interminável jogo discursivo no qual vozes em primeira e terceira pessoa, ações vividas ou meramente testemunhadas e relatos do passado e do presente, se misturam ao passo que as diferentes personagens vão se [des]encontrando no decorrer da narrativa. Essa dificuldade em conceituar o narrador de Lobo Antunes apresenta ao leitor inicialmente um desafio interpretativo. Porém, tal dificuldade resulta numa leitura sempre rica desses múltiplos narradores. Romance alheio às rotulações de ordem conceitual, As naus apresenta uma problematização na construção de suas personagens, construídos pelo narrador múltiplo de Antunes com incrível riqueza estilística, narrativa e histórica.

Tendo isso em mente, conclui-se que o autor de As naus não está interessado em expressar um único ponto de vista em sua história, algo que podemos perceber quando lemos um romance cujo narrador é onisciente, personagem ou testemunha, ou, nos termos de Genette, heterodiegetico, auodiegético ou homodiegético. Longe dessas possibilidades romanescas, em As naus o que testemunhamos são as vozes envolvidas no processo histórico de conquista, exploração e catequização, ações infligidas pelos próprios colonizadores portugueses. Embora as vozes dos conquistados, explorados ou catequizados se façam perceber em alguns momentos do texto, é no discurso desiludido dos grandes homens do sonho português que Lobo Antunes decide concentrar seu foco narrativo. Dessa coleção de personagens, concentraremos nosso comentário na recriação ficcional proposto em As naus.

Pedro Álvares Cabral, descobridor da maior colônia portuguesa, Brasil, reaparece casado com uma mulata e com um filho. Vai morar no Residencial Apóstolo das Índias, dirigido por Francisco Xavier, que acaba lhe prostituindo a esposa. Também envolvido na exploração de mulheres africanas e até portuguesas estão Manuel de Sousa Sepúlveda e Fernão Mendes Pinto. O primeiro, nobre português morto em naufrágio, o segundo, grande cronista do período de expansão mercantil lusitano. Cabral vai à Paris, aconselhado por seu amigo, Diogo Cão, outrora grande navegador, agora um velho senil que contempla o mar em busca das lembranças de velhas aventuras.

O rei Dom Manuel é retratado como um infeliz qualquer que vê em sua coroa e cetro de latão marcas do passado idealizado em seu antigo império. Quando o rei encontra seu grande navegador, Vasco da Gama, agora um jogador compulsivo de cartas, o narrador descreve o encontro sob as vaias e troças dos que estão perto nos seguintes termos:

O rei e o navegador, alheios ao cortejo de desocupados que os troçava, rindo-se do cetro e da coroa de lata, caminharam ao comprido do Tejo no sentido de Cabo Ruibo e do hidroavião roubado às ondas e mantido no seu promontório de calcário com pedaços de pano traçado pelos pássaros e as múmias dos passageiros atrás dos caixilhos das vigias. Sentiram-se finalmente 
iguais, na sua decrepitude e no seu cansaço, ao cabo de tantas separações, equívocos, amuos e intrigas de escudeiros. (ANTUNES, 1988, p. 119-120)

Rei e súdito, em igual situação: menosprezados, ultrajados, ridicularizados. Em As naus, as personagens Manuel e Gama, ambos cansados e decrépitos, caminham deixando as vozes para trás. Deixam também as lembranças varonis no distante reino de suas mentes cujas ilusões e esperanças já inexistem. Sendo possível visualizar no rei e no navegador de Antunes um símbolo do que resta da antiga Portugal, podemos notar no relato ficcional de seu maior poeta a profundidade do desencanto, perceptível igualmente nos narradores de Lobo Antunes.

Considerado o maior poeta português e um autor ao lado de Homero, Virgílio e Dante pelo gênero épico que o consagrou, Luís de Camões surge em As naus cego de um olho, sozinho e na miséria, tendo por única preocupação ter de enterrar o pai. Nessa recriação romanesca do poeta épico, tratar-se-ia apenas de uma revisão crítica do narrador de As naus do discurso histórico? Ou estaria ele reescrevendo a própria história portuguesa, ironizando-a, parodiando-a, carnavalizando-a? Por mais que tais leituras sejam possíveis, o mais surpreendente no romance é o modo essa releitura, embora crítica e ficcional, aproxima-se também do discurso tradicional histórico dedicado a essas personagens.

Num romance construído por irônicas releituras de personagens históricas, é curioso que a descrição que o narrador de Antunes faz de Camões é muito próxima da própria realidade vivida pelo poeta. Camões perdeu o olho direito ao enfrentar os mouros no estreito de Gibaltar em 1549 a serviço do rei D. João III. Mesmo tendo alcançado reconhecimento e certa notoriedade em vida, morreu pedindo ajuda aos amigos mais próximos. De seu nascimento e morte, não se tem data certa, embora se saiba que o túmulo no Mosteiro dos Jerônimos seja apenas homenagem póstuma. Camões foi enterrado numa vala comum, junto com outras vítimas da peste, perto do vilarejo de Santa Ana. Após tais dados, a idéia de que o romance de Antunes seja apenas uma desmistificação do passado perde sua base.

Parece-nos que antes de falar do presente degradado e depreciativo da Lisboa portuguesa de seu tempo, Antunes reflete em primeira instância sobre uma época que prometeu muito e que cumpriu pouco em todos os sentidos. Embora trabalhada pelo autor, tal temática não é nova, já sendo possível perceber esse desencanto ainda na obra de Camões. Sobre seus escritos, Saraiva e Lopes afirmam que para "Camões o problema central não é o de injustiças sociais (...), mas o da não correspondência entre os anseios, os valores, as razões e a realidade da vida social e material" (1996, p. 323). Quando escrevem sobre a composição de Os Lusíadas, os autores mencionam que tal dicotomia entre idealização da mãe pátria e de sua não tão ideal realidade já é evidente quando Camões escreve sua obra. O épico camoniano 
canta uma navegação gloriosa e vitoriosa que não se faz sentir de forma tão profunda e coletiva em Portugal. Contrariamente, as poucas riquezas resultantes - se comparadas com os gastos exorbitantes exigidos por elas - apenas sustentavam a família imperial e seu séquito. $\mathrm{O}$ povo em si, os idealizadores de uma ilustre nação portuguesa sendo Camões um deles, amargavam os resultados de uma realeza frágil e de um pseudo-império em franca expansão, porém de fraca dominação. Do ponto de vista religioso, político e social, Portugal foi uma falsa promessa para todos os seus súditos do século XVI, culminando com a fuga da família real para o Brasil dois séculos mais tarde e entregando a terra lusitana na mão do então novo império francês de Napoleão.

Em ensaio publicado na internet, Alvez faz um curioso comentário sobre a grafia de algumas palavras do romance. Escreve:

\begin{abstract}
Significativa é ainda a recorrência de determinados termos, como Lixboa e Reyno, na grafia quinhentista, estendendo, ao plano lingǘstico, a denúncia de uma atitude passadista na mentalidade portuguesa. De um lado, representantes de um modelo ideológico do passado, e uma grafia arcaica; de outro, o Presente que irrompe, nas referências à Revolução dos Cravos ou à perda das colônias africanas, tempo marcado pela decadência dos sonhos e mitos. (2009, digital)
\end{abstract}

A impressão que temos é que a cronologia temporal, coerente e progressiva na maioria dos romances, se esvai no texto de caráter narrativo múltiplo de As naus. Nele, passado e presente se mesclam não apenas na grafia de algumas palavras, mas também nas formulações e nas imagens a eles referido. Como exemplo, temos a descrição do antigo continente africano, que ainda guarda caracteres de selvageria e mistério, como os relatos dos descobridores dos séculos quinze e dezesseis. Por outro lado, na descrição multi-focal e multitemporal do narrador de Antunes, África é igualmente um continente com traços modernos, revolucionários e industriais. Sobre isso, Saraiva e Lopes afirmam que o romance de Antunes é o "cruzamento parodisticamente anacrônico de figuras da Expansão e de retornados da descolonização" (1996, p. 1110).

Ao final da narrativa, percebemos como esse passado anterior, utópico e idealizado, tanto do desbravador quanto do colonizado, é exorcizado no cenário do manicômio, espaço que acolhe todas as personagens do romance. Como o nosso Policarpo Quaresma, figura que poderia estar ao lado das personagens de Antunes em As naus, Camões, Xavier e Gama, entre outros tantas, encontram na clínica psiquiátrica um lar no qual possam analisar - e igualmente reviver - suas ilusões e decepções. Não há mais lugar para eles na terra lusitana. Agora sua casa é a memória dos sonhos, lar também dos grandes e antigos sonhos com a pátria gloriosa. 
No nono capítulo do romance As naus, encontramos um curioso discurso no qual essa reconfiguração de elementos históricos fica evidente, capítulo no qual centraremos nossa análise a partir de agora. Tendo por narrador Francisco Xavier, padre catequizador das Índias dominadas por Portugal, perceber-se-á o modo como o discurso colonizador dos descobridores transforma-se em desilusão e decepção na narrativa pós revolucionaria de Antunes. Sobre a obra apostólica de Francisco Xavir, Cidade afirma:

Muitos outros poderíamos ter citado, visto que, acompanhando o autor em espírito, o apostolado, no Oriente, de São Francisco Xavier, não há aspecto de vida oriental que não tenha ensejo de tratar, porque é vasta e multiforme a actividade do missionário - (...) Não importa: a toda a parte o leva o seu fervor apostólico. (1963, p. 229)

A descrição que Cidade faz de Xavier concentra-se em sua postura missionária, em seu rigor de caráter de fé que o impulsionou a lugares desconhecidos com o intuito de salvar almas e em sua completa abnegação ao privilegiar a sorte do outro em detrimento da sua. Reconstrução irônica e farsesca do santo é a caracterização que Antunes faz de seu Francisco Xavier. Percebendo esse nítido contraste entre o santo catequizador e a personagem de $A s$ naus fica a pergunta: haveria então alguma similaridade entre a personagem histórica e a fictícia? O narrador de Antunes aproxima-os no discurso carregado de forte sentido religioso. Se no primeiro temos um discurso coerente com a fé católica, no segundo percebemos uma completa confiança e certeza de que o divino está ao seu lado. Se o primeiro escrevia para catequizados, ou para pessoas a serem catequizadas, o segundo também assume tal referência discursiva. Ao ler o nono capítulo, o leitor do romance é nomeado pelo narrador, supostamente a versão romanesca de Francisco Xavier, por “ó servos do senhor”, "caríssimos irmãos" e "ó povo de Deus", não apenas aproximando o leitor atual do texto romanesco, como também o colocando no lugar dos anteriores povos colonizados.

Todavia, o discurso de Xavier não é apenas direcionado para cristãos tementes a Deus como ele. Antes, é também prova de que toda a narrativa é permeada por uma confiança irresoluta na divindade, ou senão, na instituição religiosa que julga representa-La na terra.

Deus sabe que eu não queria. Deus conhece o intimo da minha carne, a razão dos meus pecados e o labirinto das minhas intenções. Deus acompanhava-me desde a Índia, onde o meu pai, de biavaque, trabalhava de estafeta na alfândega do porto... (ANTUNES, 1988, p. 99)

... de que Deus há muito me designara seu eleito, os quais descendentes dormiam com a minha doce e compreensiva mãe sob o aqueduto de D. João V que trazia a água a Lixboa, eternamente constipados pelos pingos que se soltavam da pedra para lhes deslizarem com perfídia ao longo do rego franzido da nuca. (ANTUNES, 1988, p. 104) 
Se fossem necessárias provas, a certeza acabada de que Deus está comigo é que mandei segunda-feira, embelezadas de lantejoulas e de sailes, trinta e oito africanas para as discotecas da Avenida Almirante Reis... (ANTUNES, 1988, p. 106)

Como o Deus anterior das cruzadas medievais e também das grandes navegações, esse é o Deus responsável pela proteção e pela vitória dos fieis defensores da fé católica. A ironia é bastante contundente. Na primeira citação, a personagem Francisco Xavier é consciente de que sua divindade o acompanha desde a tenra infância, conhecendo o seu íntimo, lendo suas intenções e estando junto dele por onde for. No segundo excerto, Deus não apenas o acompanha como também o elege qual escolhido. A confiança de que seu percurso de vida tem a proteção e a destinação divina é o motivo de Xavier acreditar que até mesmo seus mais baixos atos - como o cumprimento da exigência de Fernão Mendes Pinto de conseguir pelo menos vinte e cinco mulheres para a prostituição no Residencial Apóstolo das Índias descrito na terceira citação - tem a aprovação do Criador.

Voltando a Moçambique para reaver a esposa - que havia trocado por uma passagem de retorno a Lisboa - Xavier encontra "um rei mago transviado no seu camelo e que buscava em vão, no céu de cintilações incontáveis, a estrela de Belém, com baús dados à costa, cheia de bolinhas de naftalina e sobretudos..." (ANTUNES, 1988, p. 108). A presença desse rei mago é importante, pois demonstra que, no decorrer do romance, não apenas o rei mago está a procura de uma resposta ou de uma presença divina nos céus. Todos estão. Ainda no mesmo capítulo, após a contratação das trinta e oito prostitutas, Xavier persiste em glorificar a Deus pelas bênçãos de seu bem sucedido negócio. "Em pouco tempo, e graças à benção do Pai, um desmesurado rebanho de convertidas à Fé ocupava os bairros de Lixboa até às docas de Alcântara onde o ar era de celofane em julho(...)." (Ibidem, p. 106)

Sobre o caráter catequizador descrito ironicamente no romance, Rodrigues comenta que do romance

destaca-se, claramente, o caráter absolutamente profanador, a severa denúncia de toda a hipocrisia de grande parte do discurso catequizador da Igreja. Em nome dos mais santos princípios, essa instituição permitiu a escravização e mesmo a prostituição "espiritual" de muitos de seus súditos brancos e civilizados em nome da conquista, do lucro e do poder. Isso sem se levar em conta a própria situação de exploração das mulheres, tanto patrícias quanto nativas nesse processo de ambição colonialista. Além disso, é bastante elementar o que daí se pode concluir como crítica do posicionamento da Igreja frente à própria guerra colonial. (2005, digital)

Embora acreditemos que o discurso de Antunes seja profanador apenas se relacionado com o discurso ideológico religioso, concordamos com Rodrigues ao mencionar que ao lado do discurso histórico o romance As naus representa uma exemplificação de todos os aspectos 
irracionais e bárbaros dos quais fizeram uso os colonos portugueses. É notável o contraste quando emparelhamos a narrativa de Antunes com os discursos catequizadores e conquistadores do século XV e XVI. Percebendo a ironia entre a realidade do que aconteceu, realidade demonstrada no romance em forma de paródia, e a realidade vivenciada pelos povos conquistados, Hernani Cidade escreve que "Quando os nautas do Gama desembarcaram em Calecut, foi um deles interrogado sobre os motivos da viagem, e consta que respondeu: "Vimos buscar cristãos e especiaria”. (1963, p. 19) Percebemos pela ordem das palavras de Gama que o bem material é objeto secundário diante do objetivo maior de sua navegação: salvar almas, converter gentios, levar ao arrependimento de pecados e a fé irresoluta em Cristo. Cidade continua:

\begin{abstract}
Dava o marinheiro, na singeleza da resposta, a completa finalidade dos objetivos: a mistura, bem humana, da ganância comercial com o proselitismo religioso. (...) Poderíamos traduzi-la (a frase de Gama) aproximadamente: Vimos combater o Maometano e procurar para a nossa terra base territorial que lhe garanta a autonomia política, e recursos e víveres que lhe permitam a independência econômicas. (ibidem)
\end{abstract}

Apreendemos das palavras acima que o discurso catequizador não fazia parte dos critérios adotados por Portugal na corrida imperialista do século XIX. Segundo Burns, essa dominação - em concorrência com França, Alemanha e Inglaterra - por parte de Portugal "era acompanhada pela exploração dos trabalhadores nativos. Os acordos feitos com os chefes locais, adulados pelos europeus, autorizavam o emprego de homens e mulheres em condições pouco melhores que a escravidão" (1986, p. 617). No entanto, Lobo Antunes apresenta em seu romance, logicamente de forma irônica, aspectos discursivos que recriam aspectos textuais das grandes navegações, como a promessa da salvação de almas não cristãs. Além do ouro, do trabalho escravo e da prostituição, os grandes também desejavam almas.

Como visto, o romance de Lobo Antunes é uma reescrita de um passado glorioso e decadente. Sobre os personagens Cabral, Sepúlveda, Diogo Cão, Vasco da Gama e Camões, os sentimentos que dominam tais personagens são a decepção e o abandono. É uma coleção de personagens desiludida e alquebrada, afligida por uma terra num determinado sentido igual à outra que deixaram, porém destituída de promessas, ideais e ensejos de um futuro vitorioso. Abandonados por um rei desaparecido, por uma terra que não mais os recebe e por familiares e amigos inexistentes, o que lhes resta é um hospital de tuberculosos, mais tarde uma casa de repouso para loucos. Mas que tipo de loucura aflige seus pacientes, antigos heróis da história 
e criadores da tradição literária portuguesa? A loucura utópica de acreditar numa união coletiva em busca de um bem maior: o bem na nação portuguesa.

Concluindo, tentamos organizar nesse artigo uma série de dados e informações que objetivaram apresentar novos pontos interpretativos para o romance As naus. Temos, na readaptação das personagens históricas do romance, uma possibilidade de rever o passado de suas ações como também o presente da produção de Antunes. Num segundo instante, intentamos aprofundar alguns aspectos da personagem e do narrador de Antonio Xavier, num capítulo em que se evidencia uma crítica contundente ao pensamento católico, pretensamente humanitário, que justificava a escravidão e a exploração de povos mais fracos. Pensamento baseado na crença cristã cuja igualdade e fraternidade apenas pareciam ser preponderantes. Apenas uma, das muitas desilusões dos navegadores, padres e exploradores que retornaram à antiga nação lusitana no romance de Lobo Antunes.

\section{Referências}

ALVES, Tatiana. Agosto de 2006. As naus: as amargas impressões da viagem de volta. Endereço: http://www.desfolhar.com/ensaios.html. Acesso em: julho de 2009.

ANTUNES, António Lobo. As naus. Lisboa: Edições Dom Quixote, 1988.

BURNS, Edward McNall. LERNER, Robert E. MEACHAN, Standish. História da Civilização Ocidental volume 1. Porto Alegre: Globo, 1986

CIDADE, Hemani. A Literatura Portuguesa e a Expansão Ultramarina. Coimbra: Armênio Amado, 1963.

GENETTE, Gérard. Discurso da Narrativa. Lisboa: Universidade, 1985.

MUHANA, Adna Fadul. Passado restaurado. In: Entre Clássicos volume 04, Luís de Camões. São Paulo: Editora Duetto, 2006.

SARAIVA, Antonio José. LOPES, Oscar. Lisboa: Porto Editora, 1969.

RODRIGUES, Inara de Oliveira. Julho de 2005. As naus, de António Lobo Antunes, e o percurso anti-épico da história portuguesa. Endereço:

http://coralx.ufsm.br/grpesqla/revista/num4/ass01/pag01.html. Acesso em dezembro de 2008. 